\title{
Salud es política: pensamiento social de Floreal Antonio Ferrara y sus contribuciones para repensar "lo político" en la salud*
}

\section{Health is Politics: Floreal Antonio Ferrara's Social Thinking and his Contributions to Rethink "The Political" in the Health}

\section{Saúde é política: pensamento social de Floreal Antonio Ferrara e suas contribuições para repensar "o político" na saúde}

Fecha de recepción: 12 de junio de 2017. Fecha de aprobación: 30 de agosto de 2017.

Fecha de publicación: 27 de mayo de 2019

DOI: https://doi.org/10.11144/Javeriana.rgps18-36.spps

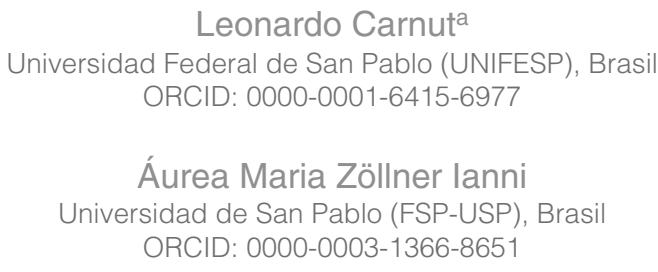

Cómo citar este artículo: Carnut L, lanni AMZ. Salud es política: pensamiento social de Floreal Antonio Ferrara y sus contribuciones para repensar "lo político" en la salud. Revista Gerencia y Políticas de Salud. 2019;18(36). https://doi.org/10.11144/Javeriana.rgps18-36.spps

Artículo de investigación

Autor de correspondencia. Correo electrónico:leonardo.carnut@ gmail.com 


\section{Resumen}

Después del golpe institucional de 2016 en Brasil, la repolitización de la salud ganó centralidad. Para reconectar el debate de la política con el campo de la salud colectiva, esta investigación revisitó la obra de Floreal Antonio Ferrara, sanitarista cuyo pensamiento crítico ayuda a repensar lo "político" en salud. Se utilizó el análisis del contenido del tomo 2 de su obra titulada Teoría política y salud, tomando como referencia teórico-conceptual lo que Júnior y Pogrebinschi delimitan como "teoría política". En un primer acercamiento, se identificó que Ferrara apuesta por el concepto de "salud" como un acto eminentemente político y sus argumentos se apoyan en un enfoque crítico marxista. Después de esta sistematización, se pudo concluir que la política no es una categoría autónoma en una sociedad capitalista y comprender que "la salud es conflicto" es saber que se trata de una pieza política no menos importante en este gran engranaje.

Palabras clave: política, ciencias sociales, salud pública, sistema único de salud, investigación cualitativa, sociología

\section{Abstract}

After the institutional setback in Brazil in 2016, the re-politicization of the health has become of central interest. In order to re-connect the political debate and the collective health issue, this research reviewed the work by Floreal Antonio Ferrara, a public health specialist whose critical thinking helps to rethink 'the political' in the health. A content analysis was applied to the Volume 2 of the Ferrara's work entitled Teoría politica y salud (Political Theory and Health) and taking as a theoretical-conceptual benchmark what Júnior and Pogrebinschi define as "political theory". A first approach identified that Ferrara takes the concept of 'health' as an almost entirely political action and that his arguments are supported by a Marxist critical approach. After systematizing these findings, it was concluded that politics is not an autonomous category within a capitalist society and understanding that "health is a conflict" means to know that health is a political component not of a lesser importance in this big picture.

Keywords: politics, social sciences, public health, sole health system, qualitative research, sociology

\section{Resumo}

Após o golpe institucional de 2016 no Brasil, a repolitização da saúde ganhou centralidade. Para reconectar o debate da política com o campo da saúde coletiva, esta pesquisa revisitou a obra de Floreal Antônio Ferrara, sanitarista cujo pensamento crítico ajuda para repensar o "político" em saúde. Utilizou-se a análise do conteúdo do tomo 2 da sua obra intitulada Teoria política e saúde, tomando como referencial teórico-conceitual o que Júnior e Pogrebinschi definem como "teoria política". Numa primeira abordagem, identificou-se que Ferrara aposta no conceito de "saúde" como ato eminentemente político e suas argumentações apoiam-se em um enfoque crítico marxista. Após essa sistematização, pode-se concluir que a política não é uma categoria autónoma em uma sociedade capitalista e compreender que "a saúde é conflito" é saber que trata de uma peça política não menos importante neste grande engrenagem.

Palavras chave: política, ciências sociais, saúde pública, sistema único de saúde, pesquisa qualitativa, sociologia 


\section{Introducción}

Desde el nacimiento de la salud colectiva en Brasil, la herencia socialdemócrata colonizó el pensamiento político de este campo (1), desalentando el desarrollo del político a través de otras matrices interpretativas. El enfoque marxista brasileño (2-4) que inicialmente conducía los debates en este campo, en los años setenta y ochenta, cedió espacio a otros saberes de orígenes postmodernos $(5,6)$ y neoinstitucionalistas $(7,8)$, abandonando gradualmente la crítica política de la ideología dominante de una manera totalizante (9).

Por esto, rescatar autores que retoman el análisis marxista del político en la salud, como Floreal Antonio Ferrara (10), es un esfuerzo por retomar la crítica. El modelo parsoniano o foucaultiano de entender los procesos de salud-enfermedad y, en consecuencia, sus opciones políticas son objetivos de este autor. Esta mirada es una importante contribución para combatir la visión hegemónicamente socialdemócrata de lo "político" que genera consecuencias problemáticas para la unidad de la acción política de la membresía de la salud colectiva en Brasil, especialmente en el golpe institucional de 2016.

Entre sus principales consecuencias, la primera fue considerar que la acción política se restringe exclusivamente al apartamiento del Estado por miembros de esta comunidad, con foco en la ejecución de políticas públicas en el ámbito del sector salud (11). Así, la lucha se ha enfocado solo en la capacidad financiero-presupuestaria del Estado con la finalidad de garantizar la viabilidad y sostenibilidad del sistema de salud, olvidándose de los movimientos populares.

La segunda fue reconsiderar la crítica marxista necesaria para la producción de la pluralidad de saberes $(12,13)$ que, en constante reelaboración, conforman el campo de la salud colectiva con sus teorías, conceptos, prácticas y métodos. En la insistencia de rechazar el marxismo, "lo político", generado por una gran cantidad de análisis de este campo (14), consolidó el discurso de la izquierda democrática sobre la coyuntura, o sea, que "hacerse cargo de las políticas públicas para ampliar la democracia en la instituciones estatales" sería la única tarea a la cual dedicarse (13). 
Ejemplos de estas consecuencias se vieron en las últimas cartas de posicionamiento político de la Asociación Brasileña de Salud Colectiva (Abrasco) en sus congresos, como el III Congreso Brasileño de Política, Planificación y Gestión en Salud (2017) (15) y el 12. ${ }^{\circ}$ Congreso Brasileño de Salud Coletiva (2018) (16). En ellos está explícita la posición socialdemócrata de defender aspectos relacionados con la gestión de los servicios de salud, sobre los modelos tecnoasistencialistas y sobre la democratización de las instituciones, sin referirse a la salud como parte integrante de un contexto político de lucha de clase en la dinámica del capital y su crisis.

Fue así cómo, especialmente después de la crisis económica y política de 2016 (2), la repolitización del debate de los sanitaristas (17) y todos los profesionales que se dedican a la construcción del Sistema Único de Salud alcanzó el máximo de urgencia, requiriendo un esfuerzo pedagógico orientado. Es necesario aclarar que la repolitización propuesta hegemónicamente por la salud colectiva brasileña se constituye en la recuperación y actualización de la reforma sanitaria en lo que sería el fortalecimiento y ampliación de la interlocución con los movimientos sociales, especialmente los vinculados a la salud y a la ciudadanía; el apoyo a la movilización social, concibiendo la salud como un derecho; y el diálogo con la sociedad (18).

Sin embargo, recuperar la politización de los trabajadores y movimientos populares en salud, con base en una reedición del abordaje socialdemócrata, sería repetir una historia de la que ya se conoce el final. Así, pensar en una propuesta de concebir la salud desde una perspectiva crítica marxista, ayudaría con miradas cualitativamente más amplias que reconecten la visión del trabajo en salud con el "todo" político-social, construyendo la crítica al Estado capitalista.

Con apoyo en la idea de "ciclicidad de la historia", se admite que, en momentos de crisis, se revise el pensamiento social en salud, en este caso, aquel que problematiza lo político. Revisar los caminos siempre oxigena y lleva a ver qué camino viene tomando el debate y cómo se puede dar una mirada que (re) vea los pasos dados por el movimiento sanitario en la discusión sobre lo "político" en la salud.

Por eso, la lectura atenta de la obra de Floreal Antonio Ferrara (19), Teoría política y salud, tomo 2, realizada por los autores de este escrito, partió con la intención de identificar cómo la categoría política, en su pensamiento 
social, se desarrolla y cómo puede ayudar a reorientar la discusión sobre política en el campo de la salud colectiva en Brasil.

Floreal Antonio Ferrara fue un gran luchador por el derecho a la salud en Argentina (20), especialmente en la provincia de Buenos Aires donde nació. Allí fue dos veces ministro de Salud de la provincia, siempre con intensas resistencias de las oligarquías médicas que se sentían amenazadas con su presencia de inspiración socialista.

Aquí se realizó un análisis del contenido del tomo 2 de su obra Teoría política y salud, tomando como referencia teórico-conceptual lo que Júnior y Pogrebinschi (21) delimitan como "teoría política", para identificar su percepción de la salud como un fenómeno político e insertado en el todo social.

Para Júnior y Pogrebinschi (21), la "teoría política" es un acto intelectual sobre el "poder" que transita entre el "deber ser" y el "es". Así, la "teoría política" se ubica en la vecindad de tres materias: la ciencia política empirista, la historia y la filosofía. Este corte ha guiado la extracción de los contenidos de la lectura sistemática del tomo del autor.

Este tipo de lectura como emprendimiento empírico posibilitó identificar su marco teórico, como también la pertinencia que su pensamiento social para repensar los contornos que el debate sobre lo "político" se viene consolidando en la salud colectiva, tradicionalmente destinada al estudio de las "políticas públicas".

En este sentido, nos pareció esencial revisar la obra de este autor, muy poco explorado por la investigación corriente en el campo, pues su compendio arroja luz al debate teórico que se agudizó en el campo de la salud colectiva en Brasil, especialmente después del golpe institucional que viene acarreando el desmontaje del derecho a la salud a pasos agigantados.

El texto está dividido en cuatro secciones que, lejos de pretender agotar el tema, sitúan, de manera general, el asunto. La primera sección contextualiza un breve relato de la biografía político-institucional y académica de Ferrara. La segunda realiza una primera aproximación a su pensamiento social sobre la "salud", que la comprende como un acto eminentemente político. La tercera, específicamente sobre el tomo 2 de la obra, profundiza en el análisis de los argumentos de Ferrara para justificar su elección de 
abordar la salud como fenómeno político en sí mismo. Y la última sección presenta una muy breve discusión.

\section{Breve relato de la biografía político-institucional y académica de Ferrara}

Ferrara centró su actividad académica en identificar la "política" (en su diversidad de significación) en la producción de la salud en general. Sus principales elaboraciones teóricas sobre la articulación entre teoría política y salud datan de 1992 con la producción de la serie Teoría política y salud, conformada por tres tomos (20).

Hijo de un carpintero anarquista yugoslavo y una ama de casa española, Ferrara nació en Punta Alta, provincia de Buenos Aires, Argentina, y ya con diecinueve años fue a estudiar a la Facultad de Medicina de la Universidad Nacional de La Plata (UNLP). Después de un periodo de formación en cardiología, se dedicó al estudio de la medicina social, la cual marcó su camino hacia la construcción de un sistema de salud sostenido por la participación popular (22).

En 1987, como ministro de Salud de la provincia de Buenos Aires, creó la atención ambulatoria y domiciliaria en salud (Atamdos), el comienzo de lo que sería la atención primaria a la salud en el sistema que ideaba. Con grupos formados por un médico, un enfermero, un psicólogo, un asistente social, un bioquímico y un odontólogo para cada dos equipos, estos se hacían socialmente responsable en un área de 300 familias. Las familias hacían la gestión local de los servicios, desde reuniones con los equipos, asambleas comunitarias, así como la administración de la nómina de los profesionales (23).

Ferrara apunta que el éxito de esa experiencia se debió a la radical participación popular en la construcción del sistema (22). La experiencia de Ferrara demostró un pionerismo en la identificación de la política (en su sentido lato) como fundamental en la sostenibilidad de los sistemas de salud, especialmente en lo que se refiere a la participación y el desarrollo de poder local en la atención primaria (ocho años antes del inicio del Programa Salud de la Familia en Brasil, por ejemplo).

En su larga trayectoria académica, Ferrara fue jefe de los estudios en la cátedra de Higiene y Medicina Social y titular de Medicina Preventiva y Social de la Facultad de Ciencias Médicas de la Universidad de La Plata. 
Fue director de los cursos de Medicina Social en el Movimiento Nacional por un Sistema Integrado de Salud en Buenos Aires, en el Posgrado en Administración de Salud y Seguridad Social de Alta Dirección en las universidades nacionales de San Martín y Tres de Febrero. Fue titular de Administración Sanitaria y de Ética en la Universidad Nacional de Lomas de Zamora y de San Martín, respectivamente, además de miembro de diversas asociaciones médicas en Argentina.

A diferencia de otros latinoamericanos que también se dedicaron al tema de "política y salud" (24), el gran interés de Ferrara se dirigía a la teoría política como el marco teórico marxista para la interpretación de la salud (19). Esto reafirma la pertinencia del estudio de esta obra del autor para verificar el potencial de contribución que ella puede tener para interpretar la salud en Brasil.

Así, el pensamiento político de Ferrara puede contribuir mucho a la formación y reorientación de la discusión política que está en pauta en el orden del día del SUS. Identificar los puntos de convergencia de sus ideas y cuáles son sus potencialidades para comprender el escenario de disputa político-ideológica en Brasil parece ser una actividad intelectual provechosa. Al final, como el propio autor ya apuntaba: "la salud es la solución del conflicto" (20).

Por todo ese personaje político e intelectual que fue Ferrara, es que su discusión sobre la "política" en el pensamiento social en salud argentino, y en cierta medida latinoamericano, nos parece sin par. Su sistematización contribuye no solo a la profundización del conocimiento sobre el autor y su obra, sino a un pensamiento crítico sobre política en salud, tan necesario en los días actuales.

\section{Revisando el pensamiento de Ferrara sobre "salud": un acto eminentemente político}

La salud colectiva en general tradicionalmente trabaja con el concepto de salud importado de la OMS ${ }^{1}$ y que, sin muchas resistencias, adhirió el vocabulario del área. En una compilación realizada por la Asociación Trabajadores del Estado (ATE), Ferrara (19) ya cuestionaba ese concepto y asumía la responsabilidad de criticarlo. A partir de un análisis de totalidad más atenta a tomar la salud como un fenómeno social, Ferrara ya apuntaba: 
La salud es una cuestión ética y política. Una dimensión esencial de la vida social y del orden político [...] y no una revolución en el bienestar, ni una solución integral para la mejora del sistema de salud, o triunfo sobre la enfermedad u optimización de la atención médica. Todas estas terapias están destinadas a un enemigo que no existe o, como máximo, a una pequeña parte de este enemigo. iEsta no es la batalla fundamental! En realidad, el enemigo está más allá, es mayor, mucho más amplio y, por lo tanto, más complejo y más difícil. Se amplía así la realidad problemática que debe afrontar, es claramente más compleja. Esta extensión del asunto, este crecimiento desenfrenado del enemigo nos hace entender la necesidad de una conciencia clara de las razones para tantos fracasos, por qué tanta muerte y enfermedad, postración y malestar. (p. 33)

\section{Y reforzaba que}

El punto central fue movido del microbio a la sociedad. De la modificación patológica del mecanismo celular, para el entendimiento de las fuerzas y relaciones sociales; de las alteraciones íntimas del protoplasma, de los núcleos, de los cromosomas, de las membranas, de los nucléolos a las relaciones de producción. Este es el cambio: rechazar el fetichismo del síntoma, de la enfermedad, para entender la causalidad estructural que lo genera. Entonces, hoy la medicina y su atención a la salud y la Epidemiología son ciencias sociopolíticas, arraigadas en la historia de los hombres y sus grupos sociales, cubriendo el análisis concreto de las relaciones de producción que determinan las situaciones sociales, políticas, económicas, jurídicas, religiosas y culturales que amenazan o perjudican las posibilidades del bienestar de las personas. (p. 33)

Con este pensamiento, hacía una contraposición clara a la imposición del orden del "bienestar" descripto por la OMS. Así, Ferrara planteaba que

Entonces los epistemólogos empezaron a preguntar. ¿Y qué quiere decir bienestar? Es decir: estar bien. [...] Comenzamos todos a pensar, todos pensábamos en esto, que era una tautología, entonces en los Estados Unidos los epistemólogos también y en Canadá particularmente empiezan a pensar cómo se puede utilizar otra palabra en lugar de bienestar porque, esa de "bienestar" es como decir: esta oficina es una oficina, esta mesa es una mesa [...] estaba afirmando la cosa en términos tautológicos. Entonces aparecieron algunas palabras. La primera palabra importante es "maduración": es un estado de madurez frente a los acontecimientos ... pero servía 
a los niños. Estar sano es ir madurando, pero no servía mucho para los adultos que ya eran maduros. Entonces empiezan a aparecer otras. Otra palabra que aparece es "equilibrio". Pero si fue imponiendo lentamente una palabra que se llama "adaptación". ¿Qué es la "adaptación"? Se adapta a una situación en la que una persona se encuentra. [...] empezamos a pensar [...]. ¿Adaptarse?! ¿Adaptarse a qué? Al sistema?! Entonces es un retroceso. $(10$, p. 40$)$

Por eso, Ferrara fue enfático en decir:

[...] entonces ahora podemos decir, para resumir, que la salud es la lucha para resolver un conflicto antagónico que quiere impedir alcanzar el ideal vital para vivir en la construcción de nuestra felicidad. (19, p. 4)

Este concepto de salud es muy provocador y controvertido para una gran parte, hoy hegemónica, de la salud colectiva. De acuerdo con Marques (25), este campp en Brasil es subsidiario intelectual del área de la política, planificación y gestión en salud, y considera insistentemente la política reducida a las normas/directrices instrumentadas de gestión de una "política pública" (de salud).

Al hecho de tomar la política en ese sentido, se desvía la atención necesaria a sus otros significados (26), especialmente en lo que concierne a la construcción de habilidades relacionadas con la militancia sanitaria, esencial para la formación social brasileña como elemento de organización de la lucha política (no institucional) por los derechos.

Ferrara, en su esfuerzo por comprender la salud como elemento constitutivo de la política del país, afirmaba:

El problema de la salud en nuestro país no es un problema aislado, o sea, la propia salud está íntimamente ligada al modelo económico y social del país. Esto forma parte de un capítulo de la llamada determinación máxima, que en términos filosóficos es llamado de sobredeterminación jerárquica, que actúa en la salud y es impuesto por el capitalismo, el imperio. (19, p. 44)

El proceso está vinculado al proceso de entrega de salud en el país. Para discutir el problema de la salud tenemos que colocarnos en lugares di- 
ferentes con cuidado. Como el filósofo Baruch Spinoza enseñó, si usted quiere saber la verdad, mire los efectos. Si usted quiere saber la verdad de la salud en nuestro país, mire los efectos. Vaya a ver cómo las niñas y los niños viven en las aldeas, mire las tasas de desnutrición, analfabetismo, vea cómo son nuestra edad, quedan enfermos y que nuestros jóvenes están muriendo, nuestros ancianos. (19, p. 42)

Pocos días antes de tomar posesión como ministro de Salud del Gobierno de Buenos Aires, Ferrara adelantó su plan de acción que aspiraba a ser la segunda revolución de la salud peronista o, como él dijo, "una medicina totalizada con la participación de la comunidad que tiende a la reconstrucción del hombre" (19, p. 10).

Nuevamente, presiones corporativas llevaron a abandonar este proyecto que duró solo 120 días. Pero esa experiencia le ayudó a argumentar que, para resolver el problema de la salud:

Debe insertarse en cualquier decisión en el campo de la participación popular de la salud. La gente tiene que ser los protagonistas del sistema de salud [...] ¿Y qué hace que la participación popular? Aquellos que hasta ahora son los usuarios de convertirse en co-gestores del sistema de salud. Que co-gobernar. (19)

Ferrara, aun impedido para ejercer su cargo, desarrolló sus ideas sobre la relación "política y salud”, utilizando su formación sociológica de inspiración marxista, siempre desde una perspectiva crítica. En la escritura del tomo 2 de Teoría política y salud intenta desarrollar mejor sus ideas.

\section{El enfoque de la salud como un fenómeno político}

En rigor, el área de la política, planificación y gestión en salud (PPGS) tiene su origen en las ciencias humanas y sociales (27), y se especula que los conocimientos esenciales para constituir el área transitan desde la ciencia política a la sociología y al derecho, pasando por las ciencias administrativas y económicas, hasta las prácticas clínicas de las diferentes categorías profesionales en salud, requiriendo de aquellos que se dedican a su estudio un esfuerzo intelectual notable. 
Sin embargo, Ferrara nos ofrece una forma diferente de comprender la salud que puede incorporar en la PPGS formas, tal vez no originales, pero sí renovadas de la salud. El autor ya presentaba su posición sobre salud como política en su primer párrafo del libro en análisis. Su posicionamiento delinea lo que, en rigor, desarrolla adelante:

La salud nunca fue lo que queríamos y nunca será lo que proponemos. Depende de otras razones que de nuestra voluntad, no es un fantasma individual, subjetivo [...] se trata de la cuestión política más importante de nuestros países. (19, p. 5)

Desde entonces el autor intenta hacer una crítica a la práctica médica tratando de identificar sus especificidades en lo que se refiere al poder. A partir de la concepción heideggeriana de verdad, Ferrara utiliza ese supuesto filosófico para hacer una crítica a esa práctica, que es considerada un a priori científico, cuando en realidad su crítica se basa en la noción de verdad de que el componente empírico de la práctica médica resulta de su acción concreta:

De los puntos de vista y desde los límites epistemológicos indicados, se puede aceptar con mejor disposición analítica, que la convocatoria de mayor exigencia se ubica en la capacidad determinante de la práctica $[\ldots](19$, p. 6)

Si quiere aquí hacer una aclaración en torno a la ontología de la práctica en general y de la práctica médica específicamente. La realización de la práctica aparece como vinculada al núcleo de una personalización inevitable y definida. Esta es una visualización de la práctica, que con tonos empíricos, resulta una percepción equivocada de la práctica del agente profesional que la ejecuta. (19, pp. 6-7)

Estas dominaciones y determinaciones no se repiten inexorablemente, ni tampoco para siempre, precisamente por el hecho de que las ciencias médicas son ciencias sociales y de los seres humanos. Esto quiere decir que, en los casos específicos, únicos, no es posible pensar en "leyes" generalizables, por tratarse de acontecimientos singulares, personales. (19, p. 8) 
Después de estos posicionamientos, Ferrara (19) delinea su opción marxista de análisis del fenómeno salud como fenómeno social, cuando apunta:

De aquí se puede partir y entonces percibir y aceptar un atrevimiento más, para así decir que la práctica médica y con amplitud operativa la práctica profesional, se puede abarcarla en profundidad si se asimila su realidad teórico-práctica como un proceso productivo de la vida sociedad. (19, p. 9)

Este proceso productivo reconoce en el proceso de trabajo su elemento inicial, indisolublemente unido y condicionado con las relaciones sociales que esa producción ha construido y construye dinámicamente. (19, p. 9)

El proceso de trabajo médico tiene que ver con las condiciones concretas, materiales y técnicas en las que se desarrolla la producción profesional. (19, p. 9)

Muy lúcido en su posición sobre cómo debe abordar la práctica médica para sacarle el idealismo inherente, señala:

Con esta visión concreta de la determinación de la fuerza o del proceso de la práctica profesional, queda alijada toda posibilidad de otorgar al acto médico cualquier concepción idealista o evocación de contenido humanista, que en el trabajo médico no pasaría de pura creación. (19, p. 10)

A esta altura de la racionalidad deberíamos introducir la convicción de que las relaciones sociales de producción señalan como condición de su existencia la presencia de una formación política e ideológica que tiene especificidad con esas relaciones sociales y que nos deben remitir a las formulaciones institucionales supraestructurales que dan características propias de esas formaciones sociales. $(19$, p. 11)

En el intento de esclarecer el proceso por el cual considera la salud como un fenómeno político inherente al "todo social”, Ferrara bautiza su explicación como "demonio" de la esencia de la salud. Por sus argumentos es posible percibir la indignación con la subordinación de la salud al "demonio" del orden capitalista: 
Así la reproducción de la fuerza de trabajo se implementa fuera del aparato productivo empresarial y para asegurar ese procedimiento debemos reconocer algunas condiciones insustituibles, entre las cuales en este instante nos interesan especialmente tres $[\ldots](19$, p. 14)

La primera condición se relaciona como salario. Su explicación ya es inevitable y está por encima de cualquier ubicación político-filosófica. $(19$, p. 14)

Otros de los dos componentes para la reproducción de la fuerza de trabajo es el Sistema Educativo. Con él se asegura la reproducción de la calificación de la fuerza de trabajo, así como la identificación de los trabajadores a las reglas del orden social imperante. (19, pp. 14-15)

Nos importa la tercera condición, la que establece el sistema sanitario no porque sea muy diferente de las otras condiciones de reproducción de la fuerza de trabajo, sino simplemente, porque en tal sistema se ejercita la denominación o la operabilidad de la práctica médico-profesional. (19, p. 15)

A continuación, a partir de la visión de Canguilhem (28), Ferarra utiliza esta epistemología para reordenar la posibilidad de abordaje del fenómeno social "salud" sin incurrir en neologismos. Así, identificando la posibilidad de una conceptualización social de la salud a partir de un intento de abarcar al máximo la totalidad de la cuestión, comienza a definir su propia concepción de salud:

En nuestra visión del conflicto, como transgresión a la norma, sirve para esa búsqueda hacia una cuidadosa y prudente generalización. En el sentido de que el hombre sólo se siente en buen estado de salud $-\mathrm{y}$ tal como es la salud - cuando más que normal, se siente normativo, apto para seguir nuevas formas de vida [...]. La salud se mide por la resolución de los conflictos, no por la ausencia de conflictos; el poder y la tentación de enfermarse, dijo el epistemólogo francés, representan una característica esencial de la fisiología humana. (19, p. 23)

El individuo forjando nuevas situaciones vitales de creación de valores, construye su situación de salud. La creación de nuevas formas, desde lo vital a lo social, desde lo social a lo vital, ambas son una, en un sentido transformador del concepto de salud que todo el dinamismo dialéctico 
de Canguilhem hace posible, en la concepción de un concepto sanitario proyectado en la sociedad. (19, p. 24)

En cuanto a otra particularidad interpretativa, Ferrara (19) se apoyará en Foucault para trazar otra línea de comprensión, especialmente relacionada con el poder de la medicina:

La fertilidad de este pensamiento [foucaultiano], aun cuando parte de la parcialidad específica de cada situación, del cotejo de cada acontecimiento, con la limitación señalada de la particularidad, resulta interesante y su aplicación nos ofrece potencialidades dignas de tener en cuenta. (19, p. 28)

El saber en medicina consiste precisamente en entrelazar lo visible y lo enunciable tal como dijo Foucault en "Vigilar y castigar": él muestra el poder como supuesta causa, pero en sentido inverso el poder agrega al saber como sustentación ineludible, porque incluso cambiando [porque se trueque por donde se trueque] "no existe relación de poder sin la constitución relativa de un campo de saber" [...] (19, p. 31)

Tanta valoración del saber es una consecuencia de la acumulación específica que se ha ido desarrollando para el crecimiento del poder de la medicina. $(19$, p. 28$)$

Por eso, Ferrara (19) insiste en que el epistemólogo francés piensa el poder más como una estrategia que como una propiedad. Pero Ferrara tiene mucha precisión en su crítica y presenta su detección de la contradicción foucaultiana:

[...] no se disipa hasta su profundidad, ni se aclara la relación de causalidad del mismo. El poder puede ser visualizado y transformado en audible y sólo quedará la convicción, menos aún que la salud-enfermedad, no aparece trama alguna en este análisis que sea capaz de contenerlo o mostrarlo. (19, p. 32)

Sigue el desconocimiento foucaultiano para la globalización del concepto como tampoco acatará la noción de "clase dirigente", de "clase dominante”, así como requiere mayor análisis y extensión conceptual para lograr certeza filosófica y política para las ideas de dominar, dirigir y gobernar, grupos de poder, aparatos del Estado [...] (19, p. 32) 
El poder así, no es una propiedad adquirida por una clase dominante, si no el ejercicio actual de su estrategia, Nuevamente el poderoso existe en el acto de ejercicio, sin que sea preciso conocer de dónde viene o quién le asigna su funcionamiento. (19, p. 35)

Y así Ferrara (19) es asertivo en lo que piensa al cerrar su argumento sobre la visión de poder foucaultiana:

Se detiene así toda modificación en límites que no van más allá de la propia lógica de cada particularidad en ciertas circunstancias, el camino emprendido sólo ha mostrado la ineficacia para la transformación de la causalidad estructural y ha conducido, en contrapartida, una formulación nihilista de pura esterilidad individual. (p. 39)

Profundo conocedor de la relación agencia-estructura para analizar la salud como fenómeno social, Ferrara sale de la crítica de la vertiente del poder más agencial para relacionarlo con la estructura, sin caer en dicotomías. En sus primeras palabras sobre cómo identifica la salud en esa relación, apunta:

La medicina está inserta en el seno del proceso social, es parte de los mecanismos que la sociedad administra para desencadenarla sobre las exigencias del ordenamiento global que necesita del funcionamiento normal de la misma sociedad. En realidad es una resultante de tal funcionamiento, pero sus elementos componentes no pueden intervenir con autonomía de la globalidad. Que actúan para completarla, pero dependen en última instancia de las condiciones impuestas por esa totalidad a la que deben contribuir. (19, p. 39)

Por más que Ferrara comprenda la salud como un sector que se encuentra en esa relación, su intento es deconstruir el pensamiento parsoniano en salud que dedica a la enfermedad a la idea de "conducta desviada" y al sector salud el locus de sistema social fundamental para el control social. Esta vez, destila su acidez (19):

Aquí comienza la tarea demoledora de la conceptualización teórica de Parsons, una complicada y denso armazón científico construido con la religiosidad de un vetusto mecanismo de relojería medieval. (p. 40) 
Ferrara (19) recoge lo que Parsons entiende por "poder":

Parsons sabe que en un sistema social el poder de un actor es siempre un poder relativo al otro actor y que tal poder es capaz de transformarse en un foco de conflictos, no precisamente armonizadores. Pero su enfoque del poder tiene especial interés por la capacidad de funcionar frente a las conductas desviadas o ante acciones indeseadas. (p. 48)

Así, la enfermedad debe considerarse como desviación del orden socialmente establecido, lo que Ferrara (19, p. 50) llama "postura individual y voluntarista de reparación de la función normalizadora”. Por lo tanto, se puede justificar y está en consonancia con el uso de la fuerza en el debate entre lo que se desea para el mantenimiento del orden y su vigencia dentro de la norma social impuesta. En ese sentido, sus rebajes en la práctica en salud generan la idea de que:

[...] la enfermedad entra como una categoría alienadora pasiva, producto de un proceso adquirido que transforma, en cierta medida, el ego que la padece. (19, p. 53)

Y pone al enfermo en una situación en la cual

Se reclama pasiva y dependiente en la esperanza y en la petición de que alguien cuide de él [...] lo que justifica la sustitución de la norma básica del sistema social, por esta nueva del sistema desviado que la enfermedad gesta. (19, p. 53)

En esta posición, Ferrara (19) concluye:

El papel de enfermo, no sólo se aísla e inusual como también expone la conducta desviada a la acción de fuerzas reintegradoras de su condición social. Esas fuerzas son las que integran el proceso de control social, con el cual se identifica la práctica médica. (p. 53)

Ferrara señala las limitaciones parsonianas y explica su opción analítica. Reconoce que su idea de poder ratifica la norma social vigente y demuestra que no es fecunda para el cambio social y, por consiguiente, del propio sector salud: 
Falta en Parsons toda mención a la historia, al sistema económico-productivo dominante como falta en toda referencia liberal-idealista ... [...] Es importante recordar que el "poder" para su convicción, resulta de la capacidad de un sistema social realizar [...] lo que se ha de realizar para alcanzar los "intereses colectivos" contra el cual en última instancia no se puede atentar. $(19$, p. 61$)$

Este pensamiento articulante se encuadra en el convencimiento de que no puede haber lucha política, en la específica acción social contra la enfermedad sin un punto estratégico general. Este es el gran vacío que se señala en la teoría de Talcott Parsons que sigue creyendo en el reconocimiento colectivo de la autoridad del médico, autoridad como atributo de un estatus en una colectividad, otorgada por motivaciones individuales, sin referencias a las condiciones de las formas productivas dominantes que son las que las sostienen. (19, pp. 62-63)

Ferrara, después de contribuir a un análisis crítico de las matrices teóricas que consideran a la salud como un fenómeno social, se ocupa de lo social y señala cómo su definición es crucial para lo que, en la época, era concebido como medicina social. Por lo tanto, va a abogar, críticamente, que:

[...] no basta con considerar, para intitularse gestor o defensor de la Medicina Social, culto de consideraciones sociales que involucran al pueblo o mencionar a los pobres ... [...] etc. Tampoco es suficiente declarar que los aspectos económicos-sociales gestados por la situación general dominan las esferas del proceso salud-enfermedad. Nada de eso sirve científicamente para otorgar categoría de tal a la Medicina Social ... [...] Se puede expresar esto y por cierto corresponder a una visión idealista, romántica y simple de la medicina, aquella que sigue señalando por ejemplo: "la esencia del" "paciente" [...] la "esencia del proceso económico-social" [...] o en fin desarrollando una teoría antropológica del proceso salud-enfermedad o una simple acumulación yuxtapuesta de aspectos biológicos, sociales y psicológicos que no son el aporte certero para resolver la categoría de ciencias de la medicina. $(19$, p. 70$)$

Y deja claro el concepto de social, tal cual debe ser comprendido por la medicina: 
Las condiciones concretas del proceso de producción de la riqueza común para la sociedad, son las que expresan la naturaleza específica de la relación que el ser humano tiene con la naturaleza y con el ámbito que lo rodea, envolviendo [...] las relaciones entre ellos [...] han sido denominadas desde casi un siglo y medio relaciones sociales de producción. En ellas precisamente están inmersos los marginados y por ahí hay que oír el horizonte del social que caracteriza a la medicina de todos los tiempos. (19, p. 70).

Ferrara (19) justifica:

Volvamos a racionalizar para buscar mayor claridad en esta complejidad. La identificación del concepto económico-social, o lo social en resumen, necesita la construcción de su concepto que exige la delimitación de la existencia y de la interrelación específica de los diferentes niveles de la estructura global de la sociedad ... [...] Este límite o en el marco de lo social, en el recorte que hacen los idealistas y / o empiristas aparece como inapropiado, como erróneo porque ... [...] ... proyectan sobre lo "real" las interrelaciones, las articulaciones y el límite arbitrario de la ideología y del espíritu que lo sostiene. Aquí está el secreto del conocimiento y, por lo tanto, el rumbo epistemológico posible. (p. 73)

Aplicado al proceso salud-enfermedad, Ferrara (19) completa:

Aquí residen las diferencias con las interpretaciones liberales, empíricas, románticas [...] Las transformaciones se generan desde el cambio de las relaciones sociales y no desde la relación interna de la salud-enfermedad. Este proceso salud-enfermedad tampoco tiene historia, ni fuerzas generadoras propias. Es una consecuencia de las relaciones sociales como compleja situación resultante de las vinculaciones determinantes de excelencia, las económico-sociales con aquellas otras como las culturales, religiosas, ideológicas, jurídicas, etc. que también interviene. Lo hacen en diferentes escalas de excelencia, según las circunstancias históricas y el nivel de participación estructural y coyuntural que esta sociedad presenta en cada caso. (19, p. 99)

En este momento Ferrara (19) parte de la contribución que la medicina social hace a considerar lo "social" en su análisis. En la perspectiva del autor, esta percepción de lo "social" que esta "rama" de la medicina aboga es infértil para consistir en una crítica precisa a la comprensión de la salud como política. En este punto, destila su crítica: 
La medicina social empírica, idealista, subjetiva e individualista sigue pensando acríticamente con una interpretación a-histórica donde el objeto sigue siendo el sujeto portador del proceso salud-enfermedad. Al dirigirse a él, a los síntomas depositados en su región individual que son la expresión de las relaciones sociales en las que se desarrolla ese "sujeto portador" [...] para nuestro interés el proceso salud-enfermedad palpitando en tal sujeto solamente afirma una que es una práctica sintomatológica cuya remoción sólo significa una terapéutica parcial, a-histórica y a-científica. (p. 100)

La salud-enfermedad no es una cuestión de microbios, disfunciones orgánicas, psicológicas, nutricionales o de compatibilidad con el ecosistema. Es mucho más importante que todas las cuestiones que también se incluyen. Se trata de una cuestión de orden social que está ligada a esa relación social vinculante que define la sociedad en la que existe. (p. 100)

En esta discusión Ferrara (19) apunta el eslabón entre el poder constitutivo de la relación de producción con la salud:

La medicina encuentra buena parte de los caminos exigibles para cumplir con el requisito de una función social de acuerdo con las necesidades de la sociedad de restablecer las condiciones de sus relaciones de producción. La ideología sanitaria [...] se pone al servicio de la vinculación de los seres humanos entre sí y sus relaciones y de cada uno de ellos con sus prácticas de trabajo por encima del conflicto social existente y permanente [...]. Esta ideología compuesta desde la teoría de la medicina reparadora de la enfermedad encerrada en una concepción organicista, medicalizante y lucrativa sirve, en mejor de los casos, para devolver al individuo a la sociedad que lo enfermó. (p. 127)

Así, Ferrara admite que el poder sanitario está cooptado por el orden del capital, con argumentos que resaltan del pensamiento marxista en su análisis:

[...] en este poder sanitario [...] se alistan los creadores de los medios de producción, de los equipos médicos, de los fabricantes de medicamentos, de los grupos profesionales que [...] organizados son los poseedores y los guardianes de la ideología sanitaria en vigencia. [...] La ideología sanitaria de la corrección del síntoma, destinada a aliviar el dolor y mitigar el sufrimiento, generalmente escondida a través de la perfección técnica de los resultados, del control eficiente de la producción de las prácticas de recuperación de la salud, encuentra razones suficientes de engaño 
tendenciales. Nadie pone en ella la razón social profunda de la causalidad sanitaria. No es la función social designada por esta composición social de nuestra formación dependiente. (19, p. 128)

El engaño consiste en que los calmantes utilizados ocultan la razón de la génesis de su dolor y él consolida su dependencia, también doble, de la clase dominante y de la ideología sanitaria que la sirve. $(19$, p. 128)

Por lo tanto, hay algo en que la salud como política debe reconectarse se desea comprender los fenómenos sanitarios más allá de la apariencia. De acuerdo con el autor:

La ideología del aparato sanitario se imprime en la forma en que la ideología del grupo dominante del Estado debe realizarse y también la forma y el sentido en que la ideología de la clase dominada puede enfrentarse y ofrecer lucha. Las ideologías no nacen en el sanitario, ni en ninguna otra formación social si no de las clases y de los grupos sociales realizadas en un sustantivo conflicto social $[\ldots](19$, p. 144)

\section{Discusión}

El pensamiento social sobre la salud en Ferrara parece bastante propicio para revisar conceptos y buscar una salida del lugar común en el que la salud colectiva tradicionalmente viene pensando la política.

En el esfuerzo por retomar la teoría social que informa a la salud colectiva, en especial el área de la política, planificación y gestión que abogó para sí el monopolio del "saber sobre política", la revisión de la obra de Ferrara tiene ese propósito de (re)informarle que hay de política en la salud más allá de las perspectivas dominantes o que refuerzan el mainstream en la acción de aislar la política de lo social.

Como apunta Souza (29, p. 51), "de la misma manera como la libertad individual abstracta se transforma", por debajo del paño "en obediencia concreta a estilos de vida pasteurizados que solo se distinguen por el 'poder de compra' diferencial, también la 'libertad política' se transforma en mero 'escenario', en mera 'representación teatral' de la formación de voluntad democrática, en mero ritual". Asistimos a eso todos los días cuando no se 
comprende que la política está en las acciones concretas de los individuos en sus respectivas las posiciones sociales y la reproducción.

Así, ante las cuestiones coyunturales, la salud colectiva tiene un largo camino por recorrer y por eso el pensamiento político de Ferrara nos parece esencial para el rescate de la política en la salud. Es necesario superar una máxima que ha confundido y despolitizado la radicalidad del movimiento de defensa del derecho a la salud en Brasil. La política no es una categoría autónoma en una sociedad capitalista, y por eso comprender que la salud es conflicto es saber que es una pieza política no menos importante en este gran engranaje.

Asimismo, con el golpe cerca, una parte de los sanitaristas siguió realizando sus análisis sobre la coyuntura social y política a partir de sus constructos teóricos, en un intento de comprender ese tiempo social que se instalaba sobre el "pre/post-golpe".

Para la mirada de izquierda en general, el golpe vivido en Brasil tiene dos grandes interpretaciones en función del enfoque político utilizado (30). En resumen, para los socialdemócratas, el problema reside en la poca capacidad de la gobernabilidad de la presidenta Roussef en construir grandes consensos en el ámbito de la institucionalidad política brasileña, marcadamente fisiologista y corrupta (31). A pesar de no haber pruebas de su culpa, Roussef no habría sido capaz de mantener la "estabilidad" de las instituciones democráticas, siendo por lo tanto objeto de un juicio político que la destituyó del poder.

Para los marxistas, el problema reside en la propia forma jurídica y no en la capacidad de articulación política o de los arreglos institucionales. Desde esta perspectiva, todo derecho es un golpe y es invocado por la burguesía cada vez que le convenga. La forma jurídica sostiene el engendramiento de la explotación del capital y de la correspondiente dominación de seres humanos sobre seres humanos (32), y cuando estos son tensados bajo lucha de clases, el capital internacional y la gran burguesía representados en el Congreso Nacional (33) ceden algunos derechos en nombre del mantenimiento de esta forma que es el marco para la reproducción del capital y para la miríada de opresiones que constituyen esta sociabilidad (32). 
En este escenario, fue elegido por el pensamiento político en el campo de la salud colectiva marcadamente aquel "político" que reitera los arreglos institucionales, o sea, el papel del Estado como ente (re)ordenador del escenario social (34), muchas veces inspirado en el análisis de Mario Testa (35). Esta vertiente apuesta por la neutralidad del Estado y su capacidad operativa de dar dirección a las políticas públicas, como si fueran sus ejecutorias, por sí solas, siempre hacia los derechos sociales, de los cuales el derecho a la salud es uno de ellos. O sea, un camino socialdemócrata.

En este sentido, reconocer la valiosa contribución de Ferrara como un autor clásico que cayó en el olvido de la medicina social en América Latina y en su homóloga salud colectiva en Brasil, nos parece esencial. Ferrara reposiciona el concepto de salud en la visión de la "totalidad social" y presenta la discusión sobre la relación política y salud en una mirada marxista que tanto hace falta, especialmente en este periodo de hegemonización de la política restringida a "lo institucional", como se ha descrito sobre la salud colectiva brasileña anteriormente.

Esta insistencia de la salud colectiva en la explicación "institucional" pudo ser identificada en diversos análisis sobre el sector salud y la actual coyuntura política brasileña, especialmente en el "calor" del golpe institucional de 2016 que depuso a la presidenta Dilma Rousseff. Entre sus principales protagonistas en el área de la salud colectiva (36-40), los argumentos transitaban desde la "angustia resignada" hasta la "teoría democrática del policy-making".

Una de las sensaciones de angustia/desilusión puede ser claramente identificada en lo que se refiere a la restricción de las medidas gubernamentales sobre el sector, como en el caso del techo para el financiamiento de la salud que pasó a regir en 2017. Esto justifica en cuanto a la forma de resistencia "no podrá ser, ni de lejos, un proyecto sectorial, demostrando cómo los conflictos relacionados con el poder político y la salud" (36) deben, necesariamente, ampliar la lectura reducida que la salud colectiva hace del tema "política".

Entre los moderados, Escorel y Arouca (40) advierten la pérdida de la capacidad política de los "consejos y conferencias de salud" como espacios de resistencia institucional. Aun admitiendo los límites de la democracia representativa parlamentaria, hay una insistencia en "suplir los déficits democráticos" del modo tradicional de formulación de políticas públicas restringido a los gestores, técnicos y burocracia gubernamental, además de parlamentarios. 
En el caso de los que se anclan en la pléyade del policy-making, los conceptos de democracia y sus infinitas cualificaciones (consensual, deliberativa, participativa, entre otras) (36-39), han servido al vocabulario maistream de análisis político en el ámbito de la salud colectiva en Brasil, lo que denota su simpática relación con la franja de espectro político del liberal al socialdemócrata cuya capacidad analítica se restringe a conservar todo como está.

Pese al esfuerzo intelectual del mainstream del pensamiento político de la salud colectiva, lo que está en juego es la capacidad del análisis de la tendencia social a largo plazo. Sociológicamente, los pensadores de la teoría política liberal (Lijphart, Dahl, Madison), que promueven la separación artificializada entre lo político y lo económico (41), como si ambos no fueran, en su esencia, relaciones sociales en sí mismas, proporciona un repertorio intelectual que poco ayuda a superar los límites analíticos que el momento exige.

Por lo tanto, partimos de un análisis marxista que considera que la crisis política que la salud colectiva intenta analizar es mucho más profunda que una crisis del "juego político". La crisis vivida en Brasil no es solo de los "diseños institucionales", sino del proceso de acumulación de capital que se manifiesta en la dinámica del bloque en el poder y en sus rebajas en la escena política.

Este supuesto no será aquí objeto de análisis en profundidad. Lo que nos interesa es reavivar en la memoria de la salud colectiva que la fragilidad y servidumbre del Estado a la lógica de los estándares de acumulación capitalista $(42,43)$ y a los intereses económicos de las "élites políticas" y sus fracciones, es siempre el horizonte en el proceso decisorio cuando se trata de los derechos sociales.

En especial, en el caso brasileño, Costa Pinto et al. (44) demuestran que el frente político desarrollista (parte de la burguesía brasileña, gobierno del Partido Obrero y segmentos específicos del movimiento sindical) y el segmento bancario-financiero fueron las principales facciones que se aliaron en el mantenimiento del poder económico en el interior del Estado. Esto refuerza en cierta medida la cita de Lobato (45) cuando afirma que "no hubo, desde la Constitución de 1988, un proyecto político explícito para la reconfiguración ampliada de los derechos sociales previstos en la Constitución". 
La perspectiva marxista considera que las consecuencias en la salud pública y en el Sistema Único del Salud (SUS) tienen su origen en tomas de decisiones políticas que restringen aún más su presupuesto, con leyes y reglas que revierten las reformas a las condiciones de trabajo y empeoran la situación de mantenimiento del sistema. Cuando ocurrió el golpe, el financiamiento del sistema fue congelado por veinte años (ley sin precedente en ningún país) (46), la contrarreforma del sector del trabajo fragilizó los acuerdos colectivos (47), y la atención primaria de salud, considerada una referencia mundial, sufrió severos retrocesos con la reformulación de la Política Nacional de Atención Básica (Portaria 2.436/2017) (48). Mientras todo esto pasaba hubo poca resistencia organizada de los trabajadores de salud.

Así, consideramos que el impeachment de la presidenta Rousseff fue una estrategia para desbloquear la acumulación capitalista, en una creencia en un reinicio neoliberal, en esta vez, ortodoxo (49). Por lo tanto, además de las concepciones de democracia burguesa (que apuestan por el procedimentalismo metodológico) y otros conceptos políticos afines a la tradición liberal, la historia una vez más demuestra que el escenario económico (acumulación del bloque en el poder) y político (juego institucional) expresan la crisis de la acumulación del capitalismo brasileño (50).

\section{Referencias}

1. Teixeira SMF, organizador. Reforma sanitária: em busca de uma teoria. São Paulo: Cortez; 1989.

2. Donnangelo MC, Pereira L. Saúde e sociedade. São Paulo: Duas Cidades; 1976.

3. Mendes-Gonçalves RB. Práticas de saúde: processos de trabalho e necessidades. São Paulo: CEFOR, Cadernos CEFOR - Textos 1; 1992.

4. Oliveira JA. Reformas e reformismo: "Democracia progressiva” e políticas sociais (ou "Para uma teoria política da reforma sanitária"). Cadernos de Saúde Pública. 1987;4(3):360-87.doi: 10.1590/S0102-311X1987000400002.

5. Merhy EE. Saúde: a cartografia do trabalho vivo, $3 .^{\mathrm{a}}$ ed. São Paulo: Editora Hucitec; 2002.

6. Feuerwerker LMC. Modelos tecnoassistenciais, gestão e organização do trabalho em saúde: nada é indiferente no processo de luta para a consolidação do SUS. Interface. Comunicação, Saúde e Educação, Botucatu. 2005;9(18):489-506. Disponible en: http://www.scielo.br/scielo.php?pid=S141432832005000300003\&script $=$ sci_abstract\&tlng $=$ pt 
7. Lima LD. Crisis y neoliberalismo: desafíos y alternativas políticas para la construcción de sistemas universales de salud en América Latina. Cadernos de Saude Publica. 2017;33:e00047517. doi: 10.1590/0102-311X00047517.

8. Machado CV. Políticas de Saúde na Argentina, Brasil e México: diferentes caminhos, muitos desafios. Ciencia \& Saude Coletiva. 2018; 23:2197-212. doi: 10.1590/1413-81232018237.08362018.

9. Löwy M, Duménil, G, Renault E. 100 palavras do marxismo. São Paulo: Cortez; 2015.

10. Svampa M. Certezas, incertezas y desmesuras de un pensamiento político: conversaciones con Floreal Ferrara. Buenos Aires: Biblioteca Nacional; 2010.

11. Fleury S. Reforma sanitária: múltiplas leituras, diálogos e controvérsias. En: Fleury S. Teoria da reforma sanitária: diálogos críticos. Rio de Janeiro: Fiocruz; 2018. p. 15-30.

12. Mendes Á, Carnut L, Mendes SJ. Para compreender os desafios atuais da saúde pública: contribuição dos trabalhadores do SUS em uma formação política crítica. En: VIII Encontro Brasileiro de Educação e Marxismo. Capitalismo, luta de classes, educação e revolução: o legado do bicentenário de Karl Marx, 2018, Cascavel - PR. Anais do VIII Encontro Brasileiro de Educação e Marxismo. Área 5: Marxismo, pedagogia socialista e formação da classe trabalhadora, v. 8.; 2018. p. 1-10. Cascavel, Paraná; Asociación Brasileña de Educadores Marxistas.

13. Dantas AV. Reforma sanitária brasileira: ainda em busca de uma teoria para um debate necessário. En: Do socialismo à democracia: tática e estratégia na reforma sanitária brasileira. Rio de Janeiro: Editora Fiocruz; 2017.

14. Teixeira CF, Vilasbôas ALQ, Paim J. Mais que nunca, é preciso lutar. Saúde em Debate. 2018;42 (n. especial 2):5-10. doi: 10.1590/0103-11042018S200.

15. Abrasco. Carta de Natal. Declaração final do $3^{\circ}$ Congresso de Política [Internet] [citado 2018 ago. 30]. Disponible en: https://www.abrasco.org.br/site/eventos/ congresso-brasileiro-de-politica-planejamento-e-gestao-em-saude/carta-de-natal-declaracao-final-3o-congresso-de-politica/28568/

16. Abrasco. Carta do Rio de Janeiro. Documento final do $12^{\circ}$ Congresso Brasileiro de Saúde Coletiva [Internet] [citado 2018 ago. 30]. Disponible en: http://www. ensp.fiocruz.br/portal-ensp/informe/site/materia/detalhe/44163

17. Brasil. Ministério da Saúde. Diretrizes operacionais dos pactos pela vida, em defesa do SUS e de gestão. Brasília: Ministério da Saúde; 2006.

18. Soares RC. A contrarreforma na política de saúde e o SUS hoje: impactos e demandas ao Serviço Social [Tese de doutorado em Serviço Social]. Universidade Federal de Pernambuco (UFPE); 2010.

19. errara FA. Teoría política y salud - tomo segundo: abordando la salud. Buenos Aires: Catálogos; 1993. 
20. Ferrara FA. Colección Laboradores de la Salud Popular. Cuadernillo 3. Rosario, Santa Fe, Argentina: Asociación de los Trabajadores del Estado; 2014.

21. Júnior JF, Pogrebinschi T. A teoria da política En: Júnior JF, Pogrebinschi T. Teoria política contemporânea - uma introdução. Rio de Janeiro: Elsevier; 2010. p. 1-10.

22. Blanco B. Debates pendientes en salud. Entrevista inédita a Floreal Antonio Ferarra, médico sanitarista recientemente fallecido [Internet] [citado 2015 oct. 10]. Disponible en: http://www.centrocultural.coop/blogs/salud/2010/04/ $\%$ E2\%80\%9Cla-salud-es-la-solucion-del-conflicto\%E2\%80\%9D-entrevista-afloreal-ferrara/

23. Pérgola F. Hitos y protagonistas: Floreal Antonio Ferrara, un sanitarista olvidado. Revista Argentina de Salud Pública. 2013;4(16):46-7. Disponible en: http://rasp. msal.gov.ar/rasp/articulos/volumen16/46-47.pdf

24. Testa M. Pensar em saúde. Porto Alegre: Artes Médicas; 1992.

25. Marques ECL, Pimenta CA. A política pública como campo multidisciplinar. São Paulo: Editora Unesp; 2013.

26. Bobbio N. Estado governo e sociedade: por uma teoria geral da política. Rio de Janeiro: Paz e Terra; 1987.

27. Paim JS, Teixeira, CFS. Política, planejamento e gestão em saúde: um balanço do estado da arte. Rev Saúde Pública. 2006;40(Esp.):73-8. Disponible e: http:// www.scielo.br/scielo.php?pid=S0034-89102006000400011\&script $=$ sci_abstract\&tlng $=\mathrm{pt}$

28. Canguilhem G. O normal e o patológico, 7. ${ }^{\mathrm{a}}$ ed. Rio de Janeiro: Forense Univesitária; 2012.

29. Souza J. Ralé brasileira: quem é e como vive. Belo Horizonte: Editora UFMG; 2009.

30. Harto-de-Vera F. Ciencia política y teoría política contemporáneas: uma relación problemática. Madrid: Editorial Trotta; 2006.

31. Valim R. Estado de exceção: a forma jurídica do neoliberalismo. São Paulo, Brasil: Contracorrente; 2017.

32. Mascaro AL. Crise e golpe. São Paulo: Boitempo; 2018.

33. Boito Júnior A. A assim chamada “crise de representação”. Margem Esquerda. 2018;31(2):29-34.

34. Fleury S. Revisitar a teoria e a utopia da reforma sanitaria. En: Fleury S. Teoria da reforma sanitária: diálogos críticos. Rio de Janeiro: Fiocruz; 2018. p. 31-84.

35. Testa, M. Pensamento estratégico e lógica de programação: o caso da saúde. São Paulo: Hucitec; Rio de Janeiro: Abrasco; 1995. 
36. Moreira MR. Reflexões sobre democracia deliberativa: contribuições para os conselhos de saúde num contexto de crise política. Saúde em Debate. 2016;40(Esp):25-38. http://www.scielo.br/scielo.php?pid=S0103-11042016000500025\&script =sci_abstract\&tlng $=$ pt

37. Souto KMB et al. Estado e políticas de equidade em saúde: democracia participativa? Saúde em Debate. 2016;40(Esp):49-62 doi: 10.1590/0103-11042016s05.

38. Rego S, Palácio M. Ética e democracia em tempos de crise. Saúde em Debate. 2016;40(Esp):63-72. Disponible en: http://www.scielo.br/pdf/sdeb/v40nspe/01031104-sdeb-40-spe-0063.pdf

39. Reis AAC et al. Tudo a temer: financiamento, relação público e privado e o futuro do SUS. Saúde em Debate. 2016;40(Esp):122-35. Disponible en: http://www. scielo.br/pdf/sdeb/v40nspe/0103-1104-sdeb-40-spe-0122.pdf

40. Escorel S, Arouca LE. Democracia e participação: para além das dicotomias. Saúde em Debate. 2016;40(Esp):39-48. Disponible en: http://www.scielo.br/scielo. php?pid=S0103-11042016000500039\&script $=$ sci_abstract\&tlng $=$ pt

41. Wood EM. Democracia contra capitalismo - a renovação do materialismo histórico. São Paulo: Boitempo; 2011.

42. Teixeira RA, Costa Pinto E. A economia política dos governos FHC, Lula e Dilma: dominância financeira, bloco no poder e desenvolvimento econômico. Econ Soc. 2012; 21(Esp):909-41. Disponible en: http://www.scielo.br/scielo.php?pi$\mathrm{d}=$ S0104-06182012000400009\&script $=$ sci_abstract\&tlng $=\mathrm{pt}$

43. Alves G. Reforma trabalhista, modernização catastrófica e miséria da república brasileira. 2017 [citado 2017 ago. 28], [aprox. 10 pág.]. Disponible em: http:// controversia.com.br/3390

44. Costa Pinto E, et al. A economia política dos governos Dilma: acumulação, bloco no poder e crise. Instituto de Economia - Universidade Federal do Rio de Janeiro. Textos para Discussão. 2016 [citado 2017 ago. 1], [aprox. 42 pág.]. Disponible en: http://www.ie.ufrj.br/images/pesquisa/publicacoes/discussao/2016/TD_IE_004_ 2016_COSTA_PINTO_et_al.pdf.

45. Lobato LVC. Políticas sociais e modelos de bem-estar social: fragilidades do caso brasileiro. Saúde em Debate. 2016; 40(Esp):87-97. doi.org/10.1590/010311042016 s08.

46. Mendes Á, Carnut L. Capitalismo contemporâneo em crise e sua forma política: o subfinanciamento e o gerencialismo na saúde pública brasileira. En: XXIII Encontro Nacional de Economia Política. 12a, 15 de junho de 2018. Niterói: UFF; 2018.

47. Alves G. O minotauro brasileiro: reforma trabalhista e desenvolvimento do capitalismo histórico no Brasil. Revista do Tribunal Regional do Trabalho da 15a. Região. 2017;1:97-108. Disponible em: https://juslaboris.tst.jus.br/bitstream/ 
handle/20.500.12178/125460/2017_alves_giovanni_minotauro_brasileiro.pd$\mathrm{f}$ ? sequence $=1$ \&isAllowed $=\mathrm{y}$

48. Mendes Á, Carnut L, Guerra LDS. Reflexões acerca do financiamento federal da atenção básica no Sistema Único de Saúde. Saúde em Debate. 2018;42:224-43. doi: dx.doi.org/10.1590/0103-11042018s115.

49. Boito Júnior A. A crise política do neodesenvolvimentismo e a instabilidade da democracia. Crít Marx. 2016;42:155-62.

50. Teixeira RA, Costa Pinto E. A economia política dos governos FHC, Lula e Dilma: dominância financeira, bloco no poder e desenvolvimento econômico. Economia e Sociedade, Campinas. 2012;21(Esp.):909-41. doi: 10.1590/S010406182012000400009 .

\section{Notas}

1 El concepto de salud adoptado por la Organización Mundial de la Salud (OMS) en 1945 señala que la salud es un bienestar físico, mental y social y no solo la ausencia de enfermedades. Este concepto, a pesar de ser muy importante en su contexto sociohistórico, como un elemento de ruptura con el modelo biomédico de asistencias a la salud hegemónico hasta entonces, también recibió diversas críticas de las cuales la de Ferrara es una de ellas. 